\title{
Clinical Characteristics and Challenges of Management of Traumatic Spinal Cord Injury in a Trauma Center of a Developing Country
}

\author{
Ayodeji Salman Yusuf ${ }^{1} \quad$ Muhammad Raji Mahmud ${ }^{1}$ Dumura Jeneral Alfin ${ }^{1}$ Samuel Isa Gana \\ Samaila Timothy ${ }^{1}$ Evaristus Emeka Nwaribe ${ }^{1}$ Nasir Kurfi Dalhat ${ }^{1} \quad$ Ajibade Afeez Aruna $^{1}$ \\ Mohammed Mansur Idris ${ }^{1}$
}

${ }^{1}$ Department of Surgery, Neurosurgery Unit, National Hospital Abuja, Abuja, Nigeria

Address for correspondence Ayodeji Salman Yusuf, FWACS, Department of Surgery Neurosurgery Unit, National Hospital Abuja, Central Business District, PMB 425, Garki Abuja FCT, Nigeria (e-mail: yasalman01@gmail.com).

J Neurosci Rural Pract 2019;10:393-399

\begin{abstract}
Background Traumatic spinal cord injury (TSCI) is a major burden in trauma care worldwide. Most victims are young, and the injury results in economic loss and psychological and social burden on the individual and the society. The outcome depends on the severity of primary spinal cord injury, interventions to prevent secondary insults to the damaged cord, and access to a specialized care. The lack of standard prehospital care and dedicated facilities for spine care coupled with challenges of inadequate health insurance coverage impact negatively on the outcome of care in patients with spinal cord injury in our practice.

Objectives This study was performed to determine the clinical profile of patients with $\mathrm{TSCl}$ and to highlight the factors that determine the early outcome in a resource-constrained trauma center.

Materials and Methods This study was a retrospective review of trauma registry and medical records of all the patients with acute TSCl at the National Trauma Center Abuja from September 2014 to December 2016.

Results A total of 133 patients with TSCI were studied. Most of these patients were young men with a mean age of 36 years. Most injury (72.2\%) occurred following motor vehicular crash affecting mainly the cervical spinal cord (62.0\%). None of the patients received standard prehospital care. Only $41.4 \%$ of the patients were transported to the hospital in an ambulance. About half (52.6\%) of the patients suffered complete spinal cord injury (the American Spinal Injury Association [ASIA] A), and pressure ulcer was the

Keywords

- challenges

- outcome

- traumatic spinal cord injury most common complication (23.3\%). Only $42 \%$ of the patients that needed surgical intervention were operated, mainly due to the inability to pay for the service. The ASIA grade on admission was the most significant determinant factor of morbidity and mortality.

Conclusion Optimal care of patients with TSCI was hindered by inadequate facilities and economic constraints.
\end{abstract}

\section{Introduction}

Traumatic spinal cord injury (TSCI) is a common injury with a worldwide prevalence of approximately 750 per million and the annual incidence appears to be rising. ${ }^{1}$ About $8 \%$ of trauma patients sustain spinal fracture ${ }^{2}$ with $22 \%$ of patients with spinal column injury suffering spinal cord injury $(\mathrm{SCI})^{2,3}$ TSCI is one of the most devastating injuries encountered in trauma care worldwide. ${ }^{4,5}$ Motor vehicular accidents and falls account for majority of the cases.,3 Most victims are young 
men in their productive age group. TSCI leads to enormous economic, psychological, and social burden to the individual and the society. ${ }^{4,5}$ Survival and functional outcome following TSCI depends on the severity of the primary injury and the magnitude of secondary injuries that develops subsequently. Secondary injury to the traumatized cord is best prevented or minimized by adequate prehospital care, specialized acute treatment, and comprehensive rehabilitation facilitated by proper funding and health insurance. ${ }^{6-8}$ Early access to specialized care after acute TSCI is associated with improved outcomes. ${ }^{9,10}$ Patients who are admitted to specialist spinal care units within 24 hours of injury had fewer secondary complications. ${ }^{9,11}$ Early admission into a specialized spinal care unit has also been found to lead to decreased in-hospital rehabilitation time compared with initial admission to a level 1 trauma care without specialist SCI expertise. ${ }^{11}$ However, factors such as older age stops at intermediate health centers, comorbidity, cervical level of injury, and fall-related SCI are associated with delay in definitive care. ${ }^{10}$

It is estimated that 3 to $25 \%$ of SCIs occur after the initial traumatic insult, either during transit to health care facility or early in the course of management. ${ }^{12}$ While approximately $90 \%$ of patients with acute TSCI were reported to have been appropriately managed with improved outcome using established guidelines, but the situation is different in most resource-constrained countries like ours. In Nigeria, there is lack of organized prehospital care and coordinated evacuation of trauma patients from scene of injury, hence victims are often transported to health facilities by relatives or bystanders, ${ }^{13,14}$ and there is virtually nonexistent of specialist SCI centers in the country.

This study was performed to determine the clinical profile of patients with TSCI and to highlight the factors that determine early outcome in a resource-constrained trauma center.

\section{Materials and Methods}

This study was a retrospective review of trauma registry, and medical records of all the patients with acute TSCI managed at the National Trauma Center Abuja from September 2014 to December 2016. Patients with clinical suspicion of traumatic spine injury without a radiological or clinical confirmation of SCI were excluded. Information retrieved includes patients' biodata, mechanism of injury, evacuation from scene of injury, prehospital care, injury-arrival time, mode of presentation to trauma center, level of spinal cord involved, in-hospital treatment, and outcome of care. The severity of injury was categorized with the American Spinal Injury Association (ASIA) Impairment Scale at admission and at time of death or discharge from the hospital. Statistical Package for Social Sciences (IBM SPSS Statistics) 20.0 (SPSS Inc., Chicago, Illinois, United States) was used for data analysis. A descriptive analysis was performed, and categorical variables were presented as absolute numbers and proportions, while continuous variables were presented as mean and standard deviations and proportions for categorical variables. Chi-square test or Fisher's exact test where applicable were used, and a $p$-value of $\geq 0.05$ was considered statistically significant.

\section{Results}

A total of 133 patients, comprising 109 (82\%) male and 24 (18\%) females, with TSCI were studied. Most of the patients (63.1\%) were young adults (age: 20-39 years) with a mean age of $36.0 \pm 12.9$ years ( - Table $\mathbf{1})$. Most injuries $(83,62.4 \%$ ) involved the cervical spinal cord followed by the thoracic segment (-Fig. 1). Motor vehicular crash (MVC) was the most common cause of injury $(96,72.2 \%$ ) and results in $81.9 \%$ of cervical and $65.6 \%$ of thoracic cord injuries. This is followed by falls from height $(19,14.3 \%)$. Falling objects caused more of thoracolumbar injuries (40\%).

About half of the injuries $(66,49.6 \%)$ occurred outside the federal capital territory. None of the patients had a standard prehospital treatment and $66.2 \%$ presented to the hospital within 24 hours. The mean injury-arrival time was $45.0 \pm$ 85.4 hours (-Fig. 2). Half of the patients $(67,50.4 \%$ ) were transported from scene of injury to the hospital in private cars or public transportation (- Table $\mathbf{1}$ ).

SCI was complete (ASIA A) in 70 (52.6\%) patients and 26 (19.5\%) patients were neurologically intact (ASIA E) at admission (-Table 1). About 90\% (63 patients) of the patients with ASIA A injury at admission remained neurologically the same at discharge. Only 4 (5.7\%) of them improved to ASIA B. Two (13.3\%) and four (44.4\%) of the patients with ASIA C and D, respectively, improved to ASIA E. The relationship between ASIA grade at admission and discharge was statistically significant $(p<0.001)$ ( - Table 2 ).

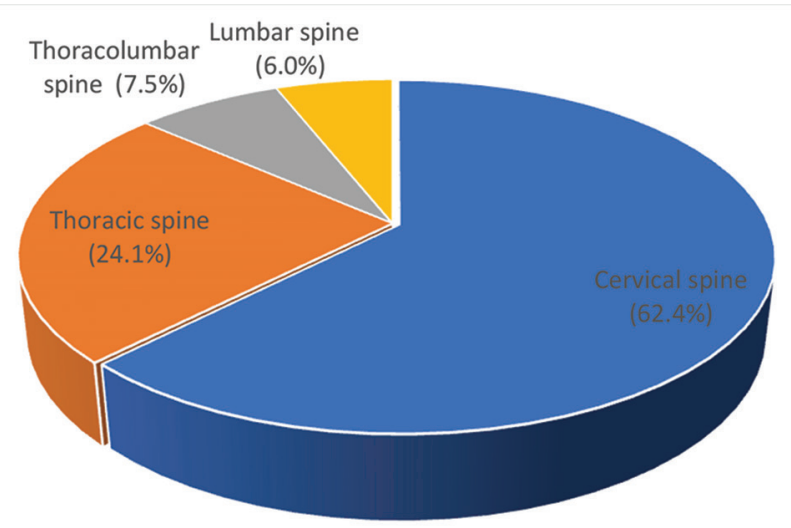

Fig. 1 Distribution of spine segment involvement.

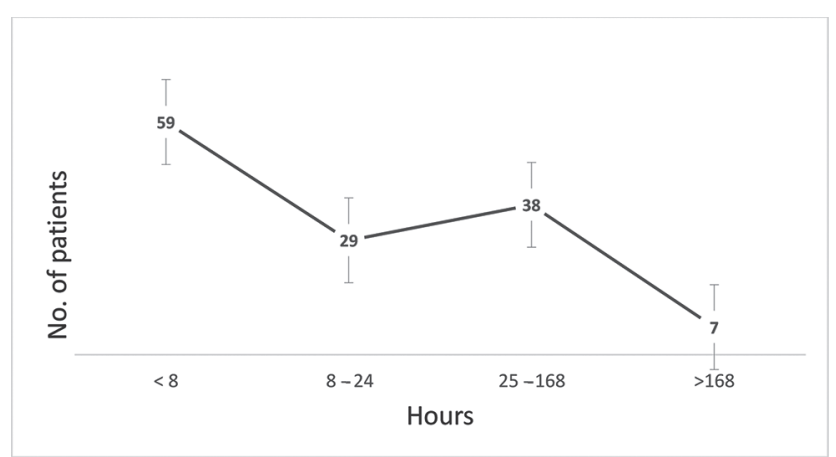

Fig. 2 Time interval between injury and presentation. 
Table 1 Patients and injury characteristics

\begin{tabular}{|c|c|c|c|c|c|}
\hline \multicolumn{6}{|c|}{ Age-sex distribution } \\
\hline \multirow{2}{*}{\multicolumn{2}{|c|}{ Patient age }} & \multicolumn{2}{|c|}{ Patient sex } & \multicolumn{2}{|c|}{ Total (\%) } \\
\hline & & Male (\%) & \multicolumn{3}{|l|}{ Female (\%) } \\
\hline \multicolumn{2}{|l|}{$<20$} & $8(7.3)$ & $1(4.2)$ & \multicolumn{2}{|l|}{$9(6.8)$} \\
\hline \multicolumn{2}{|l|}{$20-29$} & $27(24.8)$ & $8(33.3)$ & \multicolumn{2}{|l|}{$35(26.3)$} \\
\hline \multicolumn{2}{|l|}{$30-39$} & $42(38.5)$ & $7(29.2)$ & \multicolumn{2}{|l|}{$49(36.8)$} \\
\hline \multicolumn{2}{|l|}{$40-49$} & $15(13.8)$ & $2(8.3)$ & \multicolumn{2}{|l|}{$17(12.8)$} \\
\hline \multicolumn{2}{|l|}{$50-59$} & $12(11.0)$ & $4(16.7)$ & \multicolumn{2}{|l|}{$16(12.0)$} \\
\hline \multicolumn{2}{|l|}{$>60$} & $5(4.6)$ & $2(8.3)$ & \multicolumn{2}{|l|}{$7(5.3)$} \\
\hline \multicolumn{2}{|l|}{ Total } & $109(100.0)$ & $24(100.0)$ & \multicolumn{2}{|l|}{$133(100.0)$} \\
\hline & tionship betu & e mechanism & of injury and spinal co & gment injury & \\
\hline Mechanism of injury & & & Spine segment inju & & \\
\hline & Cervical (\%) & Thoracic (\%) & Thoracolumbar (\%) & Lumbar (\%) & Total (\%) \\
\hline MVC & 68 (81.9) & $21(65.6)$ & $4(40.0)$ & $3(37.5)$ & $96(72.2)$ \\
\hline Falls & $12(14.5)$ & $4(12.5)$ & $2(20.0)$ & $1(12.5)$ & $19(14.3)$ \\
\hline Gunshot & $0(0.0)$ & $2(6.2)$ & $0(0.0)$ & $1(12.5)$ & $3(2.3)$ \\
\hline Stab & $1(1.2)$ & $0(0.0)$ & $0(0.0)$ & $0(0.0)$ & $1(0.8)$ \\
\hline Falling object & $2(2.4)$ & $5(15.6)$ & $4(40.0)$ & $3(37.5)$ & $14(10.5)$ \\
\hline Total & $83(100.0)$ & $32(100.0)$ & $10(100.0)$ & $8(100.0)$ & $133(100)$ \\
\hline$p$-Value & $<0.001^{\mathrm{a}}$ & & & & \\
\hline & & tribution of inj & ury demographics & & \\
\hline & neters & & & uency $(\%)$ & \\
\hline Mechanism of injury & & & & & \\
\hline MVC & & 96( & 72.2) & & \\
\hline Falls & & 19( & 14.3) & & \\
\hline Gunshot & & $3(2$ & & & \\
\hline Stab & & $1(0$ & & & \\
\hline Falling object & & 14( & 10.5) & & \\
\hline Place of injury & & & & & \\
\hline Abuja & & 35( & 26.3) & & \\
\hline FCT & & 32( & 24.1) & & \\
\hline Outside FCT & & 66( & 49.6) & & \\
\hline Transportation mode & & & & & \\
\hline Ambulance & & 55( & 41.4) & & \\
\hline Public transport & & 10( & 7.5) & & \\
\hline Private transport & & 57( & 42.9) & & \\
\hline FRSC/police/NEMA & & 11( & 8.3) & & \\
\hline Total & & 133 & $(100.0)$ & & \\
\hline
\end{tabular}

Abbreviations: FCT, federal capital territory; FRSC, Federal Road Safety Corps; MVC, motor vehicular crash; NEMA, National Emergency Management Agency. ${ }^{\mathrm{a}} \mathrm{p}=0.001$.

Only 44 (59.5\%) of the patients needed operative intervention and had their surgery done. Surgical intervention was delayed beyond 24 hours of injury in nearly all $(40,90.9 \%)$ the patients operated. The average time interval before surgical intervention was 2 weeks after presentation. The main reason for delayed or nonsurgical intervention was financial constraints $(55,74.3 \%)$ on the part of the patients to pay for such services. Other less common causes of delay in the surgical intervention were delay in performing a radiological imaging (5.4\%) and lack of theater space (4.1\%). Ten (7.5\%) patients left the hospital against medical advice before any definitive treatment.

About one-third $(42,31.6 \%)$ of the patients developed complications, out of which pressure ulcer was the most 
common 31 (2.3\%) (-Table 3 ). The ASIA score at admission and treatment options were found to be the strongest determinants of neurological outcome at discharge. All patients with ASIA A (100\%) and $88 \%$ of patients with ASIA $B$ score at admission were neurologically nonfunctional at discharge ( $\mathbf{- T a b l e ~} 2$ ). Most of the morbidities (pressure ulcer $96.8 \%$, deep vein thrombosis/pulmonary embolism $100 \%$, multiple morbidity $100 \%$ ) were seen in patients with ASIA A and B and none in patients with ASIA D and E. More than two-thirds (77.4\%) of the patients that had delayed surgery or that were supposed to have been operated developed complications (-Table 2). Mortality was seen exclusively in patients with ASIA A and B, majority of whom $(53.8 \%)$ could not have surgical intervention due to lack of funds to finance their surgery.

\section{Discussion}

This study showed that TSCI predominantly affects young men between the ages of 20 and 39 years following MVCs. This finding is similar to reports on SCI from other parts of Nigeria ${ }^{3,15-21}$ and it reflects the global trend in the epidemiology of TSCI. ${ }^{22-24}$

Our study showed a persistent lack of prehospital care system in the management of trauma patients in Nigeria as previously reported. ${ }^{13,14}$ However, a higher percentage, $41.5 \%$, of the patients were transported in an ambulance to our facility apparently had an improvement over the 6 and $5.4 \%$ reported from other centers in Nigeria. ${ }^{13,14}$ This may be a reflection of improved ambulance services in the country in recent time or because $89.5 \%$ of our patients were referred from other hospitals and not come directly from the scene of injury. About $66.2 \%$ of the patients presented to the hospital within 24 hours of injury. The mean injury arrival time was $45.0 \pm$ 85.4 hours. Majority (60\%) of our patients that needed surgical intervention was not operated mainly because they could not pay for the service and surgical intervention was delayed beyond 24 hours in $90 \%$ of patients who were operated. In our practice, most of our patients pay out of pocket for health care due to lack of adequate universal health insurance. The fact that majority of our patients were initially admitted to an intermediate health facility and had delayed intervention in our facility was substrate for poor outcome. Contrary to our findings, Wilson et al reported $83 \%$ of patients presenting directly to site of definitive care after injury while $90 \%$ of patients with TSCI in Australia were appropriately managed using established guidelines. ${ }^{9,11}$ Patients who arrived at site of definitive care within 24 hours had significantly fewer secondary complications. ${ }^{9}$ This presupposes that other hindrances to care like finance and institutional limitations as experienced in our practice were not present. Adequate prehospital care and prompt transfer to a specialist SCI unit has been associated with improved neurological outcome. ${ }^{9}$

The cervical spinal cord segment was the most common segment injured, with the lumbar spine being the least injured segment. This finding is in keeping with publications from other authors. ${ }^{15,16,24,25}$ Few studies, however, reported lumbar spine injury as the more common spine segment affected. ${ }^{16,18,26,27}$ These later studies probably focus more on spine fractures as against SCI. Only $22 \%$ of patients with spinal injury suffer SCI.,3 Our study excluded patients without SCI.

Most of the cervical cord injuries were caused by MVC and falls, while falling objects was the most common mechanism of injury to the thoracic and lumbar spine. This finding was statistically significant. No study was found to have shown this association, although the study by Obalum et al and Solagberu showed a significant correlation between segment of spinal injury and mortality. ${ }^{16,24}$

In agreement with previous reports, only patients with incomplete SCIs showed significant neurological improvement. ${ }^{16,28-30}$ This supports the theory that complete $\mathrm{SCI}$ is a severe form of injury with poor prognosis for recovery. ${ }^{31}$

The morbidity (29.0\%) and inpatient mortality (9.2\%) observed in this study was lower than that reported previously in different regions of Nigeria. In the north-central region of Nigeria, mortality was $25.6 \%$, in the south-western region morbidity was $48.3 \%$ and mortality was $11.8 \%$, and other regions reported morbidity between 40 and $58.1 \%$ and mortality of 17.5 to $28.3 \%{ }^{13,15,16,19,30}$ Although our mortality rate is comparable with mortality of $10 \%$ reported in Botswana, it is still far above $5.8 \%$ reported among patients treated in an institution with specialist SCI unit.,10 The reduced morbidity and mortality seen in our study compared with that seen in other regions in our country may be attributed to improved care occasioned by the availability of a dedicated trauma facility and care in our institution. A decreasing mortality rate despite the same injury severity score over time has been previously reported. These improved outcomes were attributed to wider availability of specialized trauma centers, coordinated multidisciplinary care, and general improvement in trauma care. ${ }^{2,10,11}$

This study also showed that morbidity and mortality was higher in patients with complete or severe form of SCI as well as in patients who could not afford or had a delay in surgical treatment. Löfvenmark et al found that complete SCI was a strong determinant of morbidity, similarly Aarabi et al found that motor score of $<25$ and ASIA A injury were strong predictors of morbidity which is also in keeping with the finding in this study. ${ }^{6,32}$

The major challenge mitigating against optimal care of these patients in our institution is the near absence of health insurance coverage necessitating out of pocket payment for health care services. Majority of our patients (74.3\%) could not pay for their care in the immediate period after the presentation in the hospital resulting in delay in surgical intervention. It has been reported that insurance coverage improves health care utilization and posttreatment outcome. ${ }^{33}$

\section{Conclusion}

Acute TSCI is common in our practice affecting young adults, mainly due to MVC and falls and commonly involving the cervical spinal cord. The severity of injury and appropriateness of intervention were strong determinants of morbidity and mortality. Lack of prehospital care and financial constraint 
Table 2 Multivariate table showing determinants of outcomes

\begin{tabular}{|c|c|c|c|c|c|c|c|c|}
\hline \multicolumn{9}{|c|}{ Determinant of ASIA at discharge } \\
\hline $\begin{array}{l}\text { ASIA at } \\
\text { admission }\end{array}$ & $\mathrm{A}(n=63), n(\%)$ & B $(n=9), n(\%)$ & $C(n=14), n(\%)$ & \multicolumn{2}{|c|}{ D (n= 16), $n(\%)$} & $\begin{array}{c}E(n=31), \\
n(\%)\end{array}$ & $\begin{array}{c}\text { Total }(n=133), \\
n(\%)\end{array}$ & $p$-Value \\
\hline A & $63(100)$ & $4(44.4)$ & $2(14.3)$ & \multicolumn{2}{|l|}{$1(6.2)$} & 0 & $70(52.6)$ & \multirow[t]{5}{*}{$<0.001^{\circ}$} \\
\hline B & 0 & $4(44.4)$ & $6(42.9)$ & \multicolumn{2}{|l|}{$3(18.8)$} & 0 & $13(9.8)$ & \\
\hline C & 0 & 0 & $6(42.9)$ & \multicolumn{2}{|l|}{$7(43.8)$} & $2(6.5)$ & $15(11.3)$ & \\
\hline $\mathrm{D}$ & 0 & 0 & 0 & \multicolumn{2}{|l|}{$5(31.2)$} & $4(12.9)$ & $9(6.8)$ & \\
\hline$E$ & 0 & $1(11.1)$ & 0 & 0 & & $25(80.6)$ & $26(19.5)$ & \\
\hline \multicolumn{9}{|c|}{ Determinant of morbidity } \\
\hline & \multicolumn{6}{|c|}{ Morbidity } & \multirow{2}{*}{$\begin{array}{c}\text { Total } \\
(n=123), \\
n(\%)\end{array}$} & \multirow[t]{2}{*}{$p$-Value } \\
\hline & $\begin{array}{l}\text { Pressure ulcer } \\
(n=31), n(\%)\end{array}$ & $\begin{array}{c}\text { PE/DVT }(n=2) \\
n(\%)\end{array}$ & $\begin{array}{c}\text { Sepsis }(n=1) \\
n(\%)\end{array}$ & $\begin{array}{c}\text { Depression } \\
(n=10) \\
n(\%)\end{array}$ & $\begin{array}{c}\text { Multiple } \\
(n=7), \\
n(\%)\end{array}$ & $\begin{array}{c}\text { Nil }(n=81), \\
n(\%)\end{array}$ & & \\
\hline \multicolumn{9}{|l|}{$\begin{array}{c}\text { ASIA at } \\
\text { admission }\end{array}$} \\
\hline A & $27(87.1)$ & $1(50.0)$ & $1(100)$ & 0 & $6(85.7)$ & $27(33.3)$ & $62(50.4)$ & \multirow[t]{5}{*}{$<0.001^{\mathrm{a}}$} \\
\hline $\mathrm{B}$ & $3(9.7)$ & $1(50.0)$ & 0 & 0 & $1(14.3)$ & $8(9.9)$ & $13(10.6)$ & \\
\hline $\mathrm{C}$ & $1(3.2)$ & 0 & 0 & $1(100)$ & 0 & $13(16.0)$ & $15(12.2)$ & \\
\hline $\mathrm{D}$ & 0 & 0 & 0 & 0 & 0 & $9(11.1)$ & $9(7.3)$ & \\
\hline $\mathrm{E}$ & 0 & 0 & 0 & 0 & 0 & $24(29.6)$ & $24(19.5)$ & \\
\hline \multicolumn{9}{|l|}{$\begin{array}{l}\text { Treatment } \\
\text { options }\end{array}$} \\
\hline Operative & $12(38.7)$ & 0 & $1(0)$ & 0 & $5(71.4)$ & $26(32.1)$ & $44(35.8)$ & \multirow[t]{3}{*}{$0.003^{\mathrm{a}}$} \\
\hline $\begin{array}{l}\text { To be } \\
\text { operative }\end{array}$ & $12(38.7)$ & 0 & 0 & 0 & $1(14.3)$ & $11(13.6)$ & $24(19.5)$ & \\
\hline $\begin{array}{l}\text { Nonoper- } \\
\text { ative }\end{array}$ & $7(22.6)$ & $2(100)$ & 0 & $1(100)$ & $1(14.3)$ & $44(54.3)$ & $55(44.7)$ & \\
\hline & \multicolumn{6}{|c|}{ Mortality } & \multirow{3}{*}{$\begin{array}{c}\text { Total } \\
(n=123), \\
n(\%)\end{array}$} & \multirow[t]{3}{*}{$p$-Value } \\
\hline $\begin{array}{c}\text { nants of } \\
\text { mortality }\end{array}$ & \multicolumn{3}{|c|}{ Death $(n=13), n(\%)$} & \multicolumn{3}{|c|}{ Alive $(n=110), n(\%)$} & & \\
\hline $\begin{array}{c}\text { Treatment } \\
\text { options }\end{array}$ & & & & & & & & \\
\hline Operative & $3(23.1)$ & & & $41(37.3)$ & & & $44(35.8)$ & $0.01^{\mathrm{a}}$ \\
\hline $\begin{array}{l}\text { To be } \\
\text { operative }\end{array}$ & $7(53.8)$ & & & $17(15.5)$ & & & $24(19.5)$ & \\
\hline $\begin{array}{l}\text { Nonoper- } \\
\text { ative }\end{array}$ & $3(23.1)$ & & & $52(47.3)$ & & & $55(44.7)$ & \\
\hline $\begin{array}{l}\text { ASIA at } \\
\text { admission }\end{array}$ & & & & & & & & \\
\hline A & $12(92.3)$ & & & $50(45.5)$ & & & $62(50.4)$ & $0.03^{\mathrm{a}}$ \\
\hline B & $1(7.7)$ & & & $12(10.9)$ & & & $13(10.6)$ & \\
\hline $\mathrm{C}$ & 0 & & & $15(13.6)$ & & & $15(12.2)$ & \\
\hline $\mathrm{D}$ & 0 & & & $9(8.2)$ & & & $9(7.3)$ & \\
\hline E & 0 & & & $24(21.8)$ & & & $24(19.5)$ & \\
\hline Total & $13(10.6)$ & & & $110(89.4)$ & & & $123(100)$ & \\
\hline
\end{tabular}

Abbreviations: ASIA, American Spinal Injury Association; DVT, deep vein thrombosis; PE, pulmonary embolism. Note: The relationship between ASIA grade at admission and discharge was statistically significant $(p<0.001)$. 
Table 3 Distribution of treatment options, challenges of care, and morbidity

\begin{tabular}{|c|c|}
\hline Distribution of treatment options and challenges of care & Frequency (\%) \\
\hline \multicolumn{2}{|l|}{ Treatment options } \\
\hline Operative & $44(33.1)$ \\
\hline Nonoperative & $59(44.4)$ \\
\hline To be operated & $30(22.6)$ \\
\hline Total & $133(100)$ \\
\hline \multicolumn{2}{|l|}{ Time interval to surgical intervention (h) } \\
\hline$<24$ & $4(9.1)$ \\
\hline$>24$ & $40(90.9)$ \\
\hline Total & $44(100)$ \\
\hline \multicolumn{2}{|l|}{ Reason for delayed/nonsurgical intervention } \\
\hline Lack of finances & $55(74.3)$ \\
\hline Lack of implant & $1(1.4)$ \\
\hline Lack of theater space & $3(4.1)$ \\
\hline Complication/other injuries & $3(4.1)$ \\
\hline LAMA & $8(10.3)$ \\
\hline Delay in imaging & $4(5.4)$ \\
\hline Total & $74(100)$ \\
\hline \multicolumn{2}{|l|}{ Distribution of morbidity } \\
\hline Pressure ulcer & $31(23.3)$ \\
\hline PE/DVT & $2(1.5)$ \\
\hline Sepsis & $1(0.8)$ \\
\hline Depression & $1(0.8)$ \\
\hline Multiple morbidity & $7(5.3)$ \\
\hline Nil morbidity & $81(60.9)$ \\
\hline LAMA & $10(7.5)$ \\
\hline Total & $133(100)$ \\
\hline
\end{tabular}

Abbreviations: DVT, deep vein thrombosis; LAMA, leave against medical advice; PE, pulmonary embolism.

on the side of the patients constitute major challenges to ultimate care in our practice.

\section{Funding}

None.

\section{Conflict of Interest}

None declared.

\section{References}

1 Fehlings MG, Vaccaro A, Wilson JR, et al. Early versus delayed decompression for traumatic cervical spinal cord injury: results of the Surgical Timing in Acute Spinal Cord Injury Study (STASCIS). PLoS One 2012;7(2):e32037

2 Oliver M, Inaba K, Tang A, et al. The changing epidemiology of spinal trauma: a 13-year review from a Level I trauma centre. Injury 2012;43(8):1296-1300

3 Jackson AB, Dijkers M, Devivo MJ, Poczatek RB. A demographic profile of new traumatic spinal cord injuries: change and stability over 30 years. Arch Phys Med Rehabil 2004;85(11):1740-1748

4 Lifshutz J, Colohan A. A brief history of therapy for traumatic spinal cord injury. Neurosurg Focus 2004;16(1):E5
5 Ihegihu CC, Ugezu AI, Ndukwu CU, Chukwuka NC, Ofiaeli RO, Ihegihu EY. A review of traumatic spinal cord injuries at the Nnamdi Azikiwe University teaching hospital. Trop J Med Res 2014;17:31-36

6 Löfvenmark I, Hasselberg M, Nilsson Wikmar L, Hultling C, Norrbrink C. Outcomes after acute traumatic spinal cord injury in Botswana: from admission to discharge. Spinal Cord 2017;55(2):208-212

7 Burns AS, O'Connell C. The challenge of spinal cord injury care in the developing world. J Spinal Cord Med 2012;35(1):3-8

8 Divanoglou A, Westgren N, Seiger A, Hulting C, Levi R. Late mortality during the first year after acute traumatic spinal cord injury: a prospective, population-based study. J Spinal Cord Med 2010;33(2):117-127

9 Middleton PM, Davies SR, Anand S, Reinten-Reynolds T, Marial $\mathrm{O}$, Middleton JW. The pre-hospital epidemiology and management of spinal cord injuries in New South Wales: 2004-2008. Injury 2012;43(4):480-485

10 Ploumis A, Kolli S, Patrick M, Owens M, Beris A, Marino RJ. Length of stay and medical stability for spinal cord-injured patients on admission to an inpatient rehabilitation hospital: a comparison between a model SCI trauma center and non-SCI trauma center. Spinal Cord 2011;49(3):411-415

11 Wilson JR, Voth J, Singh A, et al. Defining the pathway to definitive care and surgical decompression after traumatic spinal 
cord injury: results of a Canadian population-based cohort study. J Neurotrauma 2016;33(10):963-971

12 Theodore N, Hadley MN, Aarabi B, et al. Prehospital cervical spinal immobilization after trauma. Neurosurgery 2013;72(Suppl 2):22-34

13 Adeyemi-Doro HO, Sowemimo GO. Optimal care for trauma victims in Nigeria. Trauma Q 1999;14:295-300

14 Ahidjo KA, Olayinka SA, Ayokunle O, Mustapha AF, Sulaiman GA, Gbolahan AT. Prehospital transport of spinal cord-injured patients in Nigeria. S Afr J Surg 2012;50(1):3-5

15 Nwankwo OE, Uche EO. Epidemiological and treatment profiles of spinal cord injury in southeast Nigeria. Spinal Cord 2013;51(6):448-452

16 Obalum DC, Giwa SO, Adekoya-Cole TO, Enweluzo GO. Profile of spinal injuries in Lagos, Nigeria. Spinal Cord 2009;47(2):134-137

17 Rahimi-Movaghar V, Sayyah MK, Akbari H, et al. Epidemiology of traumatic spinal cord injury in developing countries: a systematic review. Neuroepidemiology 2013;41(2):65-85

18 Odeku EL, Richard DR. Peculiarities of spinal trauma in Nigeria. West Afr Med J Niger Pract 1971;20(2):211-225

19 Igun GO, Obekpa OP, Ugwu BT, Nwadiaro HC. Spinal injuries in the Plateau State, Nigeria. East Afr Med J 1999;76(2):75-79

20 Kawu AA. Pattern and presentation of spine trauma in Gwagwalada-Abuja, Nigeria. Niger J Clin Pract 2012;15(1):38-41

21 Umaru H, Ahidjo A. Pattern of spinal cord injury in Maiduguri, North Eastern Nigeria. Niger J Med 2005;14(3):276-278

22 Gupta R, Mittal P, Sandhu P, Saggar K, Gupta K. Correlation of qualitative and quantitative MRI parameters with neurological status: a prospective study on patients with spinal trauma. J Clin Diagn Res 2014;8(11):RC13-RC17

23 Devivo MJ. Epidemiology of traumatic spinal cord injury: trends and future implications. Spinal Cord 2012;50(5):365-372
24 Solagberu BA. Spinal cord injuries in Ilorin, Nigeria. West Afr J Med 2002;21(3):230-232

25 Emejulu JK, Ekweogwu OC, Nottidge T. Patterns of spinal injury in a new neurosurgical centre: a 2-year prospective study. East Cent Afr J Surg 2009;14:76-80

26 Udosen A, Ikpeme A, Ngim N. A prospective study of spinal cord injury in the university of Calabar Teaching Hospital, Calabar, Nigeria: a preliminary report. J Orthop Surg (Hong Kong) 2006;5:1-5

27 Pirouzmand F. Epidemiological trends of spine and spinal cord injuries in the largest Canadian adult trauma center from 1986 to 2006. J Neurosurg Spine 2010;12(2):131-140

28 Ochie K, Okpala OC, Ohagwu CC, Eze CU. Profile of MRI findings and neurological impairment in spinal cord injury patients at Lagos University Teaching Hospital, Nigeria. World. J Med Sci 2013;8:418-423

29 Flanders AE, Schaefer DM, Doan HT, Mishkin MM, Gonzalez CF, Northrup BE. Acute cervical spine trauma: correlation of MR imaging findings with degree of neurologic deficit. Radiology 1990;177(1):25-33

30 Magu S, Singh D, Yadav RK, Bala M. Evaluation of traumatic spine by magnetic resonance imaging and correlation with neurological recovery. Asian Spine J 2015;9(5):748-756

31 van Middendorp JJ, Goss B, Urquhart S, Atresh S, Williams RP, Schuetz M. Diagnosis and prognosis of traumatic spinal cord injury. Global Spine J 2011;1(1):1-8

32 Aarabi B, Harrop JS, Tator $\mathrm{CH}$, et al. Predictors of pulmonary complications in blunt traumatic spinal cord injury. J Neurosurg Spine 2012;17(1, Suppl)38-45

33 Sood N, Wagner Z. Impact of health insurance for tertiary care on postoperative outcomes and seeking care for symptoms: quasi-experimental evidence from Karnataka, India. BMJ Open 2016;6(1):e010512 